\title{
IDENTIFIKASI TEMPAT TINGGAL, BEKERJA/DOMISILI DAN TUJUAN BERLIBUR PENDUDUK DENGAN DATA TWITTER
}

\author{
Studi Kasus di Jabodetabek \\ IDENTIFICATION OF RESIDENCE, WORKING / DOMICILE AND DESTINATION WITH \\ TWITTER DATA \\ Case Study in Jabodetabek \\ Nashir Wahyudi ${ }^{1}$, Robert Kurniawan ${ }^{2}$ \\ 1,2Politeknik Statistika STIS, Prodi Komputasi Statistik, Jakarta. \\ E-mail: ${ }^{1}$ 16.9325@stis.ac.id, ${ }^{2}$ robertk@stis.ac.id
}

\begin{abstract}
ABSTRAK
Twitter merupakan salah satu jejaring sosial yang sangat populer dan banyak diminati kalangan masyarakat di seluruh dunia. Dengan menggunakan informasi pada tweet akun-akun di sosial media ini kita dapat memperkirakan letak tempat tinggal serta tempat domisili dari penduduk di suatu wilayah, khususnya Jabodetabek. Penelitian ini memperkirakan jumlah penduduk yang tinggal di suatu wilayah serta tempat domisilinya di wilayah Jabodetabek berdasarkan tweet yang dilakukan. Pengolahan data untuk peneletian ini menggunakan software berikut bahasa pemrograman $\mathrm{R}$, serta aplikasi lai sebagai penunjang. Berdasarkan data yang ada dapat diketahui bahwa pengguna twitter pada bulan februari 2014 paling banyak bertempat tinggal di daerah Bekasi diikuti oleh jakarta timur dan jakarta pusat. Penduduk bekasi sendiri paling banyak berdomisili atau melakukan aktivitasnya di daerah Jakarta terutama Jakarta pusat.
\end{abstract}

Kata Kunci: Twitter; Jabodetabek; tempat tinggal.

\section{ABSTRACT}

Twitter is one of the most popular social networks, and many people use it the world. By using information on tweets accounts in this social media we can estimate the location of residence and place of domicile of the population in a region, especially Greater Jakarta. This study estimates the number of residents who live in an area and the place of domicile in the Greater Jakarta area based on the tweet. Data processing for this research is using the software also programming language $R$, and other applications as support. Based on existing data it can be seen that twitter users in February 2014 most reside in Bekasi area followed by Jakarta east and central Jakarta. The population of Bekasi itself is mostly domiciled or doing its activities in Jakarta, especially central Jakarta.

Keywords: Twitter; Jabodetabek; Residence

\section{PENDAHULUAN}

Jabodetabek adalah salah satu wilayah di indonesia yang memiliki jumlah penduduk terbanyak di Indonesia. Badan Pusat Statistik (BPS) (2018) menjelaskan bahwa, jumlah penduduk di wilayah Jabodetabek adalah sebesar 27,95 juta jiwa dengan luas wilayah 6400,71 kilometer persegi. Kepadatan penduduk di wilayah Jabodetabek sendiri di sokong dengan infrastruktur yang baik dan cukup memadai dibanding wilayah lain di Indonesia.

Kondisi ini dibarengi dengan tingginya penggunaan internet di wilayah Jabodetabek itusendiri. Berdasarkan survei yang diselenggarakan oleh lembaga Asosiasi Penyelenggara Jasa Internet Indonesia (APJII) pada tahun 2014 untuk wilayah DKI Jakarta saja terdapat sebanyak 5,6 juta orang. Jejaring sosial sendiri merupakan situs yang paling banyak diakses oleh penduduk Indonesia pada tahun 2018, yaitu sebesar $87,4 \%$ dari seluruh penduduk yang menggunakan internet.

Tingginya penggunaan jejaring sosial ini membuat salah satu situs banyak diminati selain facebook, yaitu twitter juga populer pada saat itu. Pada twitter sendiri status seseorang disebut sebagai tweets, yang biasanya berisi curhatan atau cerita tentang keseharian mereka. Selain itu, manfaat dari twitter yaitu dapat melihat pergerakan komuter seseorang di Jabodetabek (Amin, 2017). (Ajao, Hong, \& Liu, 2015) pun menjelaskan bahwa terdapat tiga tipe deteksi lokasi dengan data twitter, yaitu user home residence, tweeting location, message context. Setiap twit akan terekam sebagai raw data dengan 
variabel-variable yang terekam diantaranya waktu twit tersebut dibuat, id pembuat, lokasi dibuat, dan lain-lain.

Badan Pusat Statistik (BPS) (2014) menjelaskan bahwa komuter adalah perpindahan seseorang dari satu wilayah administrasi (Kabupaten/Kota) ke wilayah lain (beda Kabupaten/Kota) dihari yang sama. Pramana, dkk (2017) menjelaskan bahwa big data seperti twitter merupakan potensi besar bagi pemerintah untuk membuat kebijakan-kebijakan, seperti kebijakan terkait dengan pola komuter penduduk di Jabodetabek. Oleh karena itu, dengan adanya data twitter kita dapat mengetahui apakah seseorang tinggal di suatu daerah tertentu dan dimana dia melakukan aktivitas kesehariannya, serta kita juga dapat melihat secara agregat tempat tujuan seseorang ketika hari kerja atau hari libur.

\section{METODE}

Penelitian ini menggunakan data sekunder yang didapat dari PuseLab Jakarta. Data yang didapat tentunya tidak terbebas dari noise sehingga perlu dilakukan preprocessing serta cleaning sebelum dapat diolah lebih lanjut, Data Preprocessing for Data Mining addresses one of the most important issues within the well-known Knowledge Discovery from Data process. (García, S., 2014). Sehingga pemrosesan data awal menjadi salah satu langkah yang krusial dalam analisis data atau data mining. Berikut sekilas terkait data yang ada:

Tabel 1. Data Twitter

\begin{tabular}{|c|c|c|c|c|c|c|c|c|c|c|}
\hline $\begin{array}{l}\text { id_ } \\
\text { pengguna }\end{array}$ & longitude & Latitude & hari & tanggal & jam & $\begin{array}{l}\text { id_ } \\
\text { timestamp }\end{array}$ & kabupaten & $\begin{array}{l}\text { id } \\
\text { kabupaten }\end{array}$ & kecamatan & $\begin{array}{l}\text { id_- } \\
\text { kecamatan }\end{array}$ \\
\hline $1.52 \mathrm{E}+08$ & 106.7296 & -6.5614 & Sat & $22-F e b-14$ & 10.32 .58 & $1.39 \mathrm{E}+09$ & BOGOR & 3201 & DRAMAGA & 3201060 \\
\hline $3.77 E+08$ & 106.8576 & -6.29859 & Wed & 26-Feb-14 & 15.42 .42 & $1.39 \mathrm{E}+09$ & $\begin{array}{l}\text { JAKARTA } \\
\text { TIMUR }\end{array}$ & 3172 & $\begin{array}{l}\text { PASAR } \\
\text { REBO }\end{array}$ & 3172010 \\
\hline $1.55 \mathrm{E}+09$ & 106.8831 & -6.12734 & Tue & 25-Feb-14 & 15.14 .05 & $1.39 \mathrm{E}+09$ & $\begin{array}{l}\text { JAKARTA } \\
\text { UTARA }\end{array}$ & 3175 & $\begin{array}{l}\text { TANJUNG } \\
\text { PRIOK }\end{array}$ & 3175030 \\
\hline $5.8 \mathrm{E}+08$ & 106.7539 & -6.29249 & Tue & $25-$ Feb-14 & 22.48 .16 & $1.39 \mathrm{E}+09$ & $\begin{array}{l}\text { TANGERANG } \\
\text { SELATAN }\end{array}$ & 3674 & $\begin{array}{l}\text { CIPUTAT } \\
\text { TIMUR }\end{array}$ & 3674050 \\
\hline $1.85 \mathrm{E}+08$ & 106.829 & -6.15858 & Tue & 18 -Feb-14 & 15.29 .18 & $1.39 \mathrm{E}+09$ & $\begin{array}{l}\text { JAKARTA } \\
\text { PUSAT }\end{array}$ & 3173 & $\begin{array}{l}\text { SAWAH } \\
\text { BESAR }\end{array}$ & 3173070 \\
\hline $1.16 \mathrm{E}+09$ & 106.8168 & -6.31701 & Mon & 17-Feb-14 & 12.41 .49 & $1.39 \mathrm{E}+09$ & $\begin{array}{l}\text { JAKARTA } \\
\text { SELATAN }\end{array}$ & 3171 & JAGAKARSA & 3171010 \\
\hline
\end{tabular}

Pada tabel 1 diatas terlihat bahwa, data yang digunakan memiliki dua belas variabel dan 1.048.576 baris dengan dimensi wilayah, yaitu Jabodetabek dan waktu perekaman adalah bulan februari 2014.

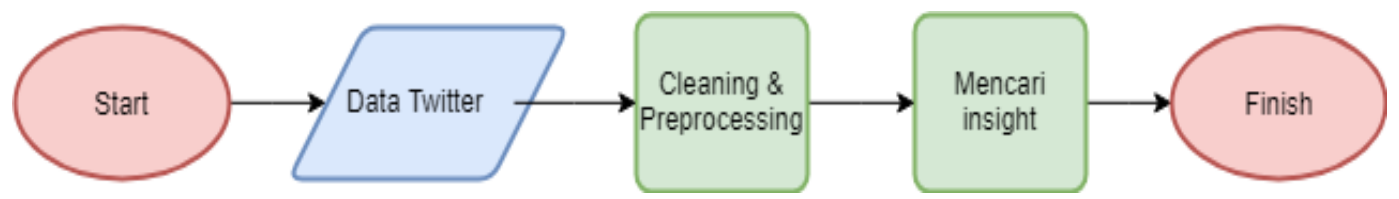

Gambar 1. Flowchart pengolahan data

Gambar 1 diatas merupakan flowchart yang menggambarkan proses yang dilakukan dalam pengolahan data yang ada. Seperti terlihat bahwa identifikasi dari tempat tinggal, tempat kerja, dan komuter pengguna pada hari libur dilakukan setelah cleaning dan preprocessing dilakukan sebelumnya. Dalam tahap cleaning dan preprocessing beberapa hal yang dilakukan diantanya adalah pelabelan variabel, imputasi missing value, dan menghilangkan outlier/anomali yang ada.

\section{HASIL DAN PEMBAHASAN}

Berdasarkan hasil pengolahan yang telah dilakukan, peneliti membuat plot-plot sebagai persentasi dari insight yang telah didapat. Peneliti menggunakan aplikasi tableau sebagai penunjang untuk membuat plot-plot yang menarik. 


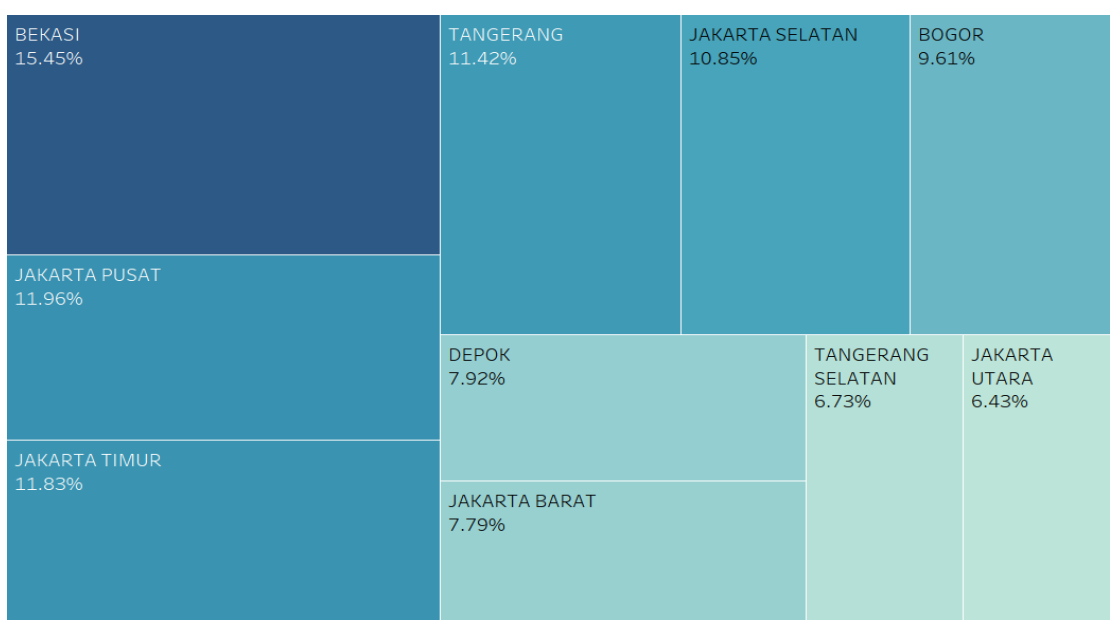

Gambar 2. Tempat tinggal pengguna twitter pada Kabupaten/Kota pada bulan Februari 2014

Pada gambar 2 diatas, bekasi adalah kota dengan tempat tinggal penduduk yang teridentifikasi paling banyak, yaitu sebesar $15,45 \%$ diikuti oleh Jakarta Pusat, yaitu sebesar $11,96 \%$ Jakarta Timur, yaitu sebesar $11,83 \%$ dari seluruh pengguna twitter yang tercatat twitnya. Wilayah dengan tempat tinggal penduduk paling sedikit adalah wilayah Jakarta Utara dengan persentase sebesar $6.43 \%$.

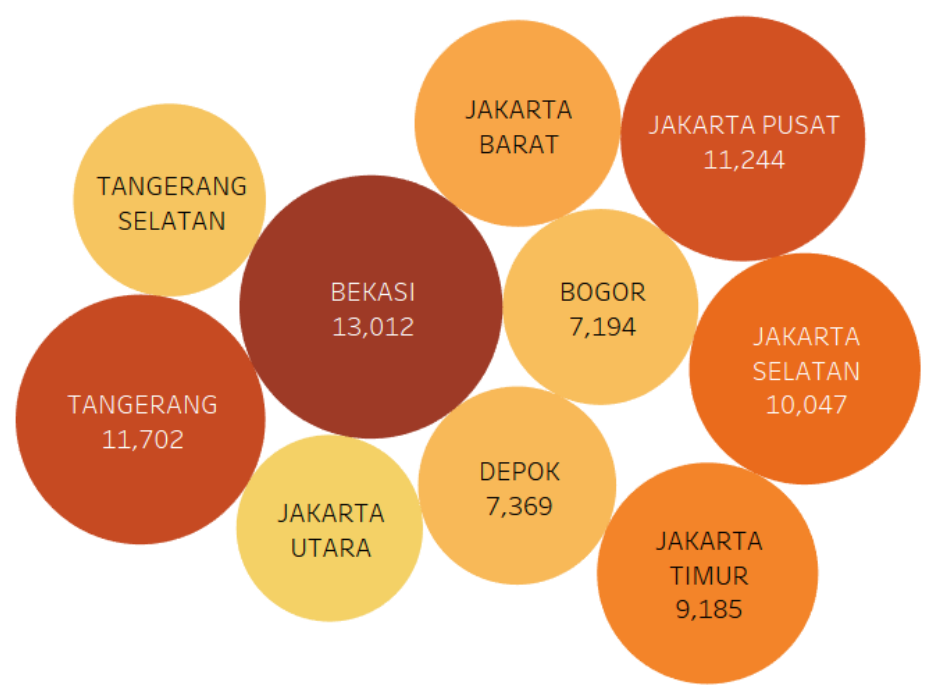

Gambar 3. Tempat kerja atau domisili pengguna twitter pada 7 Kabupaten/Kota pada bulan Februari 2014

Pada Gambar 3 diatas menampilkan jumlah pengguna twitter yang berdomisili di tujuh Kabupaten/Kota terbanyak dari sepuluh Kabupaten/Kota di Jabodetabek. Berdasarkan diagram diatas dapat terlihat bahwa Kota Bekasi merupakan wilayah domisili dengan jumlah pengguna twitter terbanyak, yaitu sebanyak 13.012 pengguna, kemudian diikuti Kota Tangerang pada posisi kedua, yaitu sebanyak 11.702 pengguna dari seluruh pengguna twitter di wilayah Jabodetabek. Wilayah domisili dengan pengguna twitter paling sedikit adalah Jakarta Utara, yaitu sebanyak 6.535 pengguna.

Dari dua plot perbandingan diatas teriindikasi bahwa daerah dengan jumlah penduduk yang menggunakan twitter paling banyak, juga memiliki pekerja paling banyak. Walaupun ada perbedaan urutan pada kota Tangerang, Jakarta Timur, dan Jakarta Pusat namun perubahannya tidak signifikan. Sehingga, kemungkinan besar penduduk yang tinggal di suatu wilayah juga berdomisili di wilayah tersebut. 


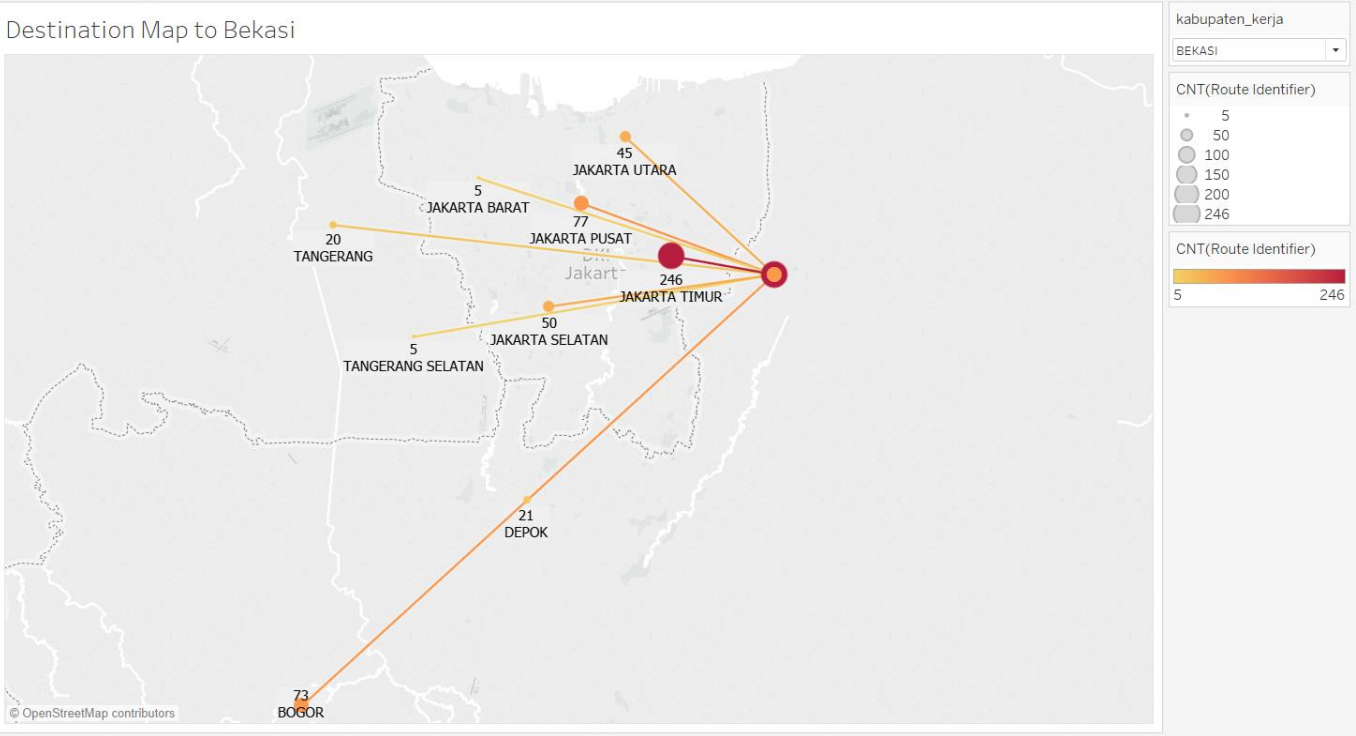

Gambar 4. Destination map penduduk yang bekerja di Bekasi

Gambar 4 diatas menunjukkan bahwa penduduk yang bertempat tinggal di bekasi paling banyak berdomisili di Jakarta Pusat, Jakarta Timur, dan Jakarta Selatan, yaitu sebesar 173, 166, 104 jiwa. Sedangkan daerah dengan domisili penduduk bekasi tersedikit adalah Tangerang, yaitu hanya 11 orang. Kondisi ini sangat timpang jika dibandingkan dengan penduduk yang berdomisili di wilayah bekasi, yaitu sebesar 7.383 orang.

Tabel 2. Origin Destination matrix penduduk Jabodetabek pada bulan Februari 2014

\begin{tabular}{ccccccccccccc}
\hline & \multicolumn{10}{c}{} & \multicolumn{10}{c}{ Tujuan } \\
\cline { 2 - 11 } & & BEKASI & BOGOR & DEPOK & JAKBAR & JAKPUS & JAKSEL & JAKTIM & JAKTARA & TANGERANG & TANGSEL & jumlah \\
\hline \multirow{4}{*}{ Asal } & BEKASI & 65581 & 560 & 159 & 96 & 882 & 427 & 1494 & 217 & 49 & 33 & 69498 \\
& BOGOR & 459 & 45707 & 867 & 262 & 440 & 309 & 217 & 23 & 91 & 53 & 48428 \\
& DEPOK & 165 & 592 & 31163 & 95 & 475 & 784 & 432 & 37 & 64 & 274 & 34081 \\
& JAKBAR & 56 & 38 & 36 & 35737 & 777 & 775 & 128 & 538 & 1125 & 227 & 39437 \\
& JAKPUS & 408 & 336 & 190 & 656 & 50392 & 709 & 787 & 578 & 437 & 136 & 54629 \\
& JAKSEL & 322 & 471 & 977 & 266 & 1196 & 45951 & 629 & 81 & 659 & 651 & 51203 \\
& JAKTIM & 1216 & 194 & 450 & 75 & 1034 & 1558 & 46215 & 407 & 84 & 66 & 51299 \\
& JAKTARA & 413 & 59 & 118 & 583 & 765 & 142 & 365 & 28615 & 70 & 17 & 31147 \\
& TANGERANG & 77 & 159 & 167 & 614 & 486 & 465 & 73 & 118 & 47773 & 1693 & 51625 \\
& TANGSEL & 40 & 140 & 256 & 48 & 280 & 643 & 88 & 19 & 652 & 26804 & 28970 \\
\hline & jumlah & 68737 & 48256 & 34383 & 38432 & 56727 & 51763 & 50428 & 30633 & 51004 & 29954 & 460317 \\
\hline
\end{tabular}

Dari tabel diatas dapat diketahui bahwa sama seperti hari kerja kebanyakan penduduk yang menggunakan twitter di suatu wilayah lebih memilih untuk berada di daerahnya sendiri pada saat hari libur, yaitu hari sabtu dan minggu. Pada hari libur daerah Jakarta Selatan menjadi daerah dengan pendatang terbanyak, yaitu sebesar 5.252 orang pendatang. Daerah yang paling sedikit didatangi oleh penduduk Jabodetabek adalah Tangerang Selatan dengan hanya 2.166 jiwa.

Pola pergerakan penduduk dilihat menggunakan circosplot (Kurniawan, 2016), dari jumlah pengguna twitter di masing-masing Kab/Kota di Jabodetabek pada hari libur, yaitu hari Sabtu dan Minggu. Berdasarkan gambar 5 dibawah dapat diketahui bahwa pola pergerakan pada hari libur, para pengguna twitter dari daerah Jakarta Timur, Paling banyak melakukan pergerakan ke arah Jakarta Selatan (lihat pita warna biru). Hal ini diduga karena di Jakarta Selatan ada beberapa tempat wisata yang murah-meriah seperti kebun binatang ragunan, Setu Babakan, Pay Park Kemang, dan lain sebagainya. Pada pita Merah yaitu Kota Bekasi, terlihat pergerakan penduduknya paling banyak di hari libur ke arah Jakarta Timur. Hal ini diduga mereka melakukan pergerakan pada daerah wisata Taman Mini Indonesia Indah (TMII) atau ke Taman buah Mekar Sari. Penduduk di Kota Tangerang, paling banyak bergerak ke arah Kota Tangerang Selatan. Hal ini diduga di daerah Kota Tangerang Selatan lebih banyak Mall dibandingkan dengan Kota Tangerang. Penduduk Jabodetabek pengguna twitter 
paling sedikit yang melakukan kegiatan komuter pada hari Sabtu dan Minggu adalah Kota Jakarta Utara, disusul Kota Bogor dan Kota Depok.

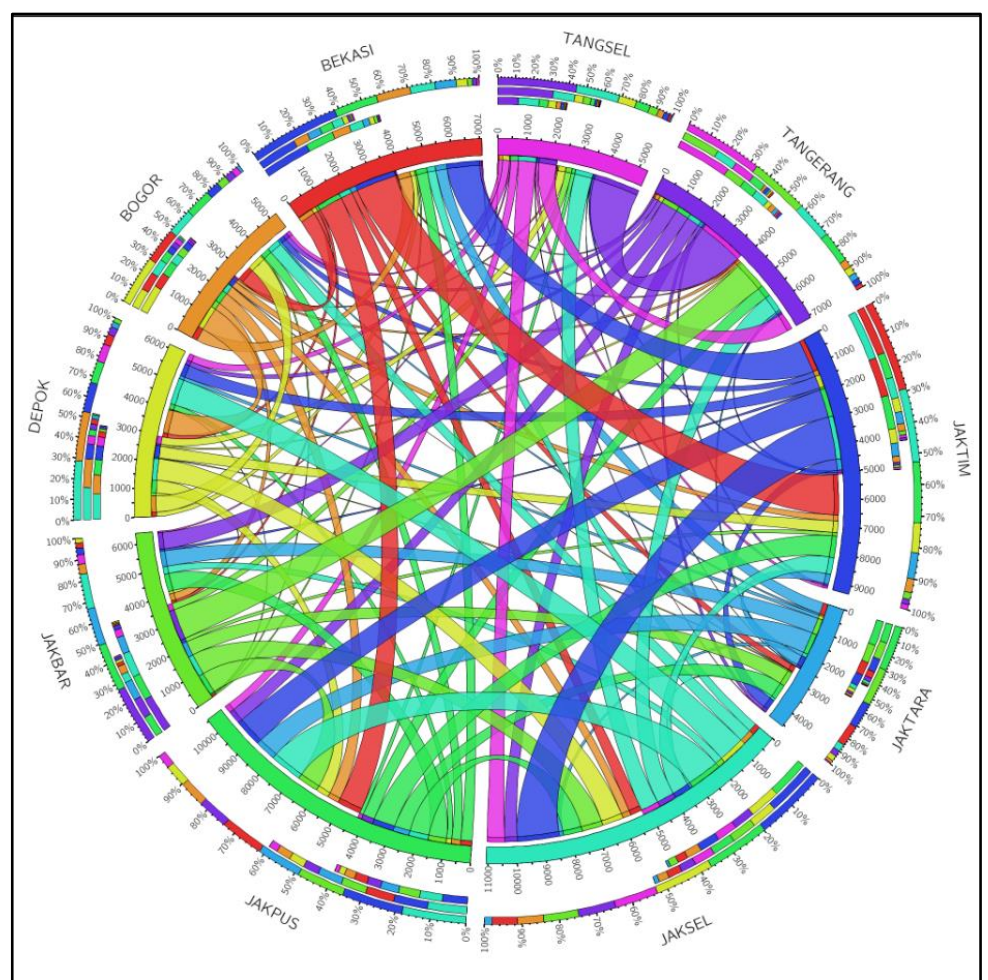

Gambar 5. Circlos plot pengguna twitter di wilayah Jabodetabek pada hari libur di bulan Februari 2014

\section{KESIMPULAN}

Pada bulan Februari tahun 2014 wilayah Jabodetabek dengan tempat penduduk paling teridentifikasi paling banyak berdasarkan data twitter adalah kota Bekasi, dengan persentase sebesar $15.45 \%$ atau sebesar 8.686 jiwa dari seluruh pengguna twitter yang tercatat di wilayah Jabodetabek. Bekasi menjadi tempat dengan domisili penduduk terbanyak, yaitu sebesar 13.012 penduduk dibanding daerah lainnya di Jabodetabek.

Sedangkan wilayah yang paling banyak didatangi pada hari sabtu dan minggu adalah wilayah Jakarta Selatan, yaitu sebanyak 5.252 orang dan yang paling sedikit adalah Tangerang Selatan dengan 2.166 jiwa. Hal ini mungkin disebabkan karena destinasi wisata yang ada di Jakarta Selatan seperti, Kebun binatang ragunan, Setu Babakan, Playparq Kemang, dll.

Kesimpulan dapat kita ambil berdasarkan hasil diatas, adalah penduduk Jabodetabek pengguna twitter, pada hari Sabtu dan Minggu tetap melakukan aktivitas komuternya pada wilayah terdekat dari domisilinya. Misalnya Dari Kota Bekasi ke Kota Jakarta Timur. Dari Jakarta Timur ke Jakarta Selatan, dan dari Kota Tangerang ke Kota Tangerang Selatan. Namun menurut, (Ma, Li, Yuan, \& Baver, 2013) informasi Origin Destination yang dihasilkan dengan pendekatan OD pada big data seperti log GPS memiliki bias terhadap kondisi tertentu sehingga terkadang tidak mewakili pola mobilitas masyarakat secara keseluruhan, terutama jika sampling rate-nya rendah atau datanya sedikit. Sehingga kedepannya diperlukan penelitian lebih lanjut untuk mendapat hasil dengan bias minimal dan lebih representatif tentunya.

\section{DAFTAR PUSTAKA}

Badan Pusat Statistik (BPS). 2014. Statistik Komuter Jabodetabek: Hasil Survei Komuter Jabodetabek 2014. BPS. Jakarta.

Amin, I., PP, N. L. P. S., Riyadi, Y., Lee, J. G., Pramana, S., \& Kurniawan, R. (2017). Inferring commuting statistics in greater Jakarta from social media locational information from mobile devices.

Asosiasi penyelenggara Jasa Internet Indonesia, "Profil Pengguna Internet Indonesia 2014". Diakses tanggal 16 Juli 2018. https://apjii.or.id/content/read/39/27/PROFIL-PENGGUNA-INTERNET-INDONESIA-2014 
Kurniawan, R. (2016). APLIKASI CIRCOS PLOT SEBAGAI ALTERNATIF EKSPLORASI DATA: MIGRASI KOMUTER JABODETABEK TAHUN 2014. Jurnal Statistika Universitas Muhammadiyah Semarang, 4(2).

Pramana, S., Yuniarto, B., Kurniawan, R., Yordani, R., Lee, J., Amin, I., \& Indriani, R. (2017, September). Big data for government policy: Potential implementations of Bigdata for official statistics in Indonesia. In 2017 International Workshop on Big Data and Information Security (IWBIS) (pp. 17-21). IEEE.

Pramana, S., Yordani, R., Kurniawan, R., \& Yuniarto, B. (2017). Dasar-dasar Statistika dengan Software R Konsep dan Aplikasi. Bogor: in media. p, 167-176.

García, S., Luengo, J., \& Herrera, F. (2014). Data Preprocessing in Data Mining. Intelligent Systems Reference Library.

Badan Pusat Statistik. "Luas Daerah Administrasi Menurut Kabupaten/Kota Administrasi, 2009-2013". Diakses tanggal 16 Juni 2018. https://jakarta.bps.go.id/statictable/2015/04/20/58/luas-daerah-administrasimenurut-kabupaten-kota-administrasi-2009-2013.html

Ajao, O., Hong, J., \& Liu, W. (2015). A survey of location inference. Journal of Information Science, 1-10.

Ma, J., Li, H., Yuan, F., \& Baver, T. (2013). Deriving Operational Origin-Destination Matrices From Large Scale Mobile Phone Data. International Journal of Transportation Science and Technology, 183-204. 